mendation that the university should concentrate on post-experience courses rather than the more conventional postgraduate courses which are taken immediately after graduation. It identifies two types of postexperience course: those needed by people who have to make a significant shift into a different type of activity, like scientists going into management; and those needed periodically by people who simply want to keep up with developments in their own field. Both types should be provided by the university, although it seems likely that the rate at which they can be introduced will depend on the availability of broadeasting time. On research, the report simply says that the staff of the university "would be able to devote a significant proportion of their time to private study and research", without suggesting how much. This, no doubt, will be for the staff of the university to decide.

\title{
Towards More Legislation on Drugs
}

The immediate response of the British Government to the report of the Wootton Committee on cannabis published two weeks ago has been firm and predictable. On two occasions in the House of Commons in the past week, Mr James Callaghan, the Home Secretary, has made no bones about his unwillingness to change the law so as to provide more lenient penalties for cannabis than for other drugs of dependence. On both occasions, Mr Callaghan was echoed by Mr Quintin Hogg, the spokesman on this subject for the Opposition in the House of Commons. Although there has been no formal opportunity to count heads, it does seem very much as if most Members of Parliament share the views of the Home Secretary, and that the "pot lobby" as he called it has a very long way to go in Britain.

The essence of what the Home Secretary had to say on January 23 was that he finds it hard to reconcile the view of the committee that the wider use of cannabis should not be encouraged with its advocacy of less stern penalties for the possession of cannabis than for other drugs. For one thing, he complained that the committee had not forecast the likely consequences of such a decision. He went on to say that if the British Government were to reduce the penalties on cannabis, people would think that "the government takes a less than serious view of drug taking". He emphasized that the British Government's position is still defined by its adherence to the resolution of the United Nations Commission on Narcotic Drugs, which last year recommended that "all countries increase their efforts to eradicate the abuse and illicit traffic in cannabis".

In a debate on the Wootton report on Monday this week, Mr Callaghan did also acknowledge that the committee had fairly argued that the law is now satisfactory in some respects, although it seems clear that Mr Callaghan had principally in mind the way in which people have recently been prosecuted for allowing their houses to be used for smoking cannabis without having known that this was being done. Mr Callaghan's case for saying that no changes are needed in the law was strengthened by the way in which one of the most remarkable cases of this kind-the conviction of a young woman because the tenants of her rented house were found with cannabis-had only a few days earlier been dismissed after a legal appeal to the House of Lords.

The way in which the WHO Expert Committee on Drug Dependence came out last week with a reaffirmation of its previous view that cannabis must continue to be controlled will do very little to clarify public or even official attitudes towards the drug. The publication of the committee's sixteenth report coincided with the meeting in Geneva of the United Nations Narcotics Commission. The report repeats what the committee has said on previous occasions-that "cannabis is a drug of dependence, producing public health and social problems, and that its control must be continued". The section on cannabis goes on to say that there is a need for "more basic data" on the acute and chronic effects of cannabis on the individual and society before an accurate assessment can be made of the degree of hazard to public health. The isolation and synthesis of the tetrahydrocannabinols have made the problem more urgent. There is nothing in the report to echo or even deny the view of the Wootton Committee (see Nature, 221, 205; 1969) that the effects of cannabis are usually so much less severe than those of other drugs that penal systems should be less severe on cannabis.

Mr Callaghan's declarations on both occasions make it plain, however, that the British Government is planning a thorough revision of the law on drug abuse. For one thing, the Home Secretary is worried about the potentialities of drugs only newly synthesized or isolated from natural materials-he singled out STP for special mention earlier this week. But he also acknowledges the need for extra flexibility, not so much by varying the penalties to suit the drug (the courts can do that if they wish) but by providing the authorities with an opportunity to move quickly whenever this should seem necessary. On Monday this week, Mr Callaghan said that he would like not to have to rely on voluntary agreements with manufacturers to keep specified drugs off the market, that he is alarmed at the way in which doctors "are prescribing in ways quite opposed to all the social views of the House of Commons" and that there is a danger that "each new fashion of drug taking will find new gaps in our defences'". What he is looking for-and working onis a "single comprehensive code to rationalize and strengthen government powers and to allow them to act flexibly in the difficult and dangerous problems likely to arise in the years ahead".

Cannabis is, however, by no means the committee's chief concern. The meeting last September on which the new report is based seems to have been intended, by the WHO secretariat, to provide background material for the reassessment of the international regulations on the control of drugs which is now being carried out by the United Nations Commission on Narcotic Drugs. Although the WHO has no formal influence on the decisions of the commission, its pronouncements do inevitably carry weight. On this 
occasion, the commission is especially concerned to review the present regulations for the international control of drugs and to draft a code (for approval by governments) which may eventually replace the Single Convention on Narcotic Drugs which has been in force since 1961, and which seems in practice to have been found at once too complicated and too rigid for easy operation.

From this point of view, the WHO committee echoes a good deal of Mr James Callaghan's disquiet about the condition of the British law on drugs. It is, for example, particularly concerned to anticipate the problems of dealing with drugs which are not at present under international control. The report puts forward two specific tests-each sufficient by itself-for deciding whether a particular drug should be brought under control. First, a drug may be "abused other than sporadically or in a local area and the effects of its abuse extend beyond the drug taker; in addition, its mode of spread involves communication between. existing and potential drug takers, and an illicit traffic in it is developing". Second, a drug may be intended for medical use but there may be experimental evidence to show a liability to "significant psychic and physical dependence" and the drug may be commercially available. In both kinds of situations, the committee argues, there is a need of control. To those who ask whether ethyl alcohol is covered by one or other of the criteria, there is no explicit ruling from the committee, but, instead, an endorsement of an earlier committee's view that "dependence on alcohol and other drugs" creates "major health problems".

The chief administrative product of the committee's work is a list of five categories of drugs of different types not at present subject to international control. The starting point for this classification is the committee's view that the kind of control applied to any drug must be determined partly by its potential danger and partly by the extent to which it is used in medicine. Another objective is flexibility, at least so as to be able to accommodate new drugs as they are synthesized. On this basis, the committee has put forward the following classification of drugs:

1. Drugs which are accepted in medicine but with a high degree of risk (LSD and the cannabinols, for example) to which the most stringent controls should be applied.

2. Drugs widely used in medicine but with a substantial risk to public health as in barbiturate or amphetamine dependence, and which should be used under strict control only in medical practice.

3. Drugs which belong essentially to category 2 but which are less dangerous and therefore require less strict control. 4. Drugs such as the belladonna alkaloids which require even less strict control.

5. Drugs such as the antihistaminos where the committee proposes that governments should be kept informed.

Dr D. C. Cameron, the secretary of the WHO committee, said on the telephone earlier this week that it seemed very much as if the United Nations Commission would drop the last of these categories from the protocol now being drafted, but that there would probably remain five different levels at which control could be applied. He explained that one objective in the new protocol had been a wish to avoid a situation in which governments seeking to devise new legislation for new drugs would adopt inharmonious rules.
TRANSPORT

\section{Box of London Roads \\ from our Planning Correspondent}

Discussion about the Greater London Council's plans for building rings of motorways through inner London has at last come out into the open, and all the signs point to a full scale row. Work on the innermost ringway, Ringway 1 (formerly known as the motorway box), has already started in a fow places. Four motorway rings are proposed by the GLC-the north and south orbital roads outside the built-up area; the Ringway 3 or D ring road running roughly along the outskirts of the GLC boundary; the north and south circular or $\mathrm{C}$ ring (Ringway 2); and the motorway box, Ringway 1, connecting Willesden and Hackney to the north and Battersea and Blackheath to the south.

The GLC plan for this network of primary roads is to be backed up by improved secondary feeder roads to carry traffic to and from the ringways. The whole scheme, which will be published later this month and which the Minister of Housing will consider later in the year in the context of the Greater London Development Plan, is estimated to cost about $£ 1,100$ million. There will be a further considerable sum for landscaping and the like, and no costs have been calculated for compensation to families living close to the motorways and forced to leave their homes through inconvenience. These estimates mean that the GLC will spend no less than $\mathfrak{f 8 6 0}$ million on the motorway network.

In general, the outer two rings are acceptable to most critics, although the precise routing is controversial. It is argued that the rings would benefit Londoners by routing traffic round the city instead of through it; the roads will be relatively inexpensive to build by comparison with central London because of the lower cost of land, fewer families would need to be displaced and there would be less hardship and inconvenience all round.

It is against the inner two roads that there are the strongest objections. The most vociferous objectors are Mr Ben Whittaker, MP for Hampstead, and $\mathrm{Mr}$ Douglas Jay, MP for Battersea North, and his London Motorway Action Group formed to present a unified front against the plans.

All the critics seem to agree on basic points. First, the public has been presented with a fait accompli and there should be a thorough, independent inquiry to study all aspects of the scheme before it is too late. Second, the total cost of the motorway box ( $\$ 425$ million) is out of all proportion to the benefits from it-it will contribute hardly anything to the rushhour congestion. Third, the roads will reinforce the physical departmentalism of London. Fourth, the estimates of the numbers of cars and the population in central London on which the GLC based its plans may turn out to be too high. Fifth, the planners will skimp on landscaping and development around the motorways. Last and not least, the box alone will result in some 40,000 families losing their homes and at least that number will be inconvenienced and may be forced to leave their homes through fumes and noise. But there is also the view that the GLC should have taken more account of radical changes in the character of private transport between now and the end of the century, and that it should also have sought to improve public transport. 